\title{
A ESCOLA NORMAL SECUNDÁRIA DE SÃO PAULO E SEU LABORATÓRIO DE PSICOLOGIA
}

\author{
REGULAR SECONDARY SCHOOL IN SÃO PAULO AND ITS PSYCHOLOGY LAB
}

\author{
Rodrigo Lopes Miranda" \\ Universidade Católica Dom Bosco (UCDB)
}

\section{CENTOFANTI, R.; TOMASINI, M. B. O livro dos cem anos do Laboratório de Psicologia Experimental da Escola Normal Secundária de São Paulo (1914-2014). São Paulo: [s.n.], 2014.}

A obra O livro dos cem anos do Laboratório de Psicologia Experimental da Escola Normal Secundária de São Paulo (1914-2014) foi escrita por Rogério Centofanti e Maristela Bleggi Tomasini (2014). O livro chama a atenção por alguns fatores, especialmente pelas escolhas de escrita, das fontes de pesquisa e das formas de abordar a documentação primária e o objeto de pesquisa. Ele nos auxilia a compreender flertes e interseções entre a história da educação e a história da psicologia, a partir do enfoque na Escola Normal Secundária de São Paulo (Escola Normal da Praça), criada em 1894. Especificamente, os autores abordam o laboratório de psicologia experimental instalado na Escola em 1914 com o intuito de celebrar o centenário de um dos primeiros laboratórios de psicologia com interesses educacionais instalados no país. Entretanto, como veremos, seus autores foram além dessa celebração.

Rogério Centofanti é um pesquisador autônomo em história da psicologia e vem, há anos, estudando os laboratórios de psicologia experimental no Brasil. São de sua autoria as primeiras produções, propriamente ditas historiográficas, sobre a história dos laboratórios de psicologia no país (CENTOFANTI, 1982). Maristela Tomasini tem pesquisado memória social e bens culturais desde seu Mestrado. Ela trabalha com cartulários e com a construção de memórias e práticas culturais presentes em tal documentação (ver TOMASINI, 2013). Dessa forma, duas formações distintas se complementaram na obra em questão.

Esse tipo de produção, na interface entre história da educação e história da psicologia, tem sido comum na contemporaneidade,

http://dx.doi.org/10.1590/0102-4698144287

"Doutor em Educação pela Universidade Federal de Minas Gerais (UFMG). Atualmente, professor do Programa de Pós-Graduação em Psicologia da Universidade Católica Dom Bosco (UCDB). E-mail: rlmiranda@ucdb.br 
especialmente no Brasil. De acordo com Campos (2008), essas interseções no campo historiográfico se devem a conexões existentes entre a expansão dos sistemas de ensino de massa e a produção dos primeiros estudos psicológicos, cujo intuito era a aplicação da psicologia em problemas sociais e educacionais. Os estudos na interface história da educação e psicologia focam diferentes objetos. Por exemplo, há trabalhos cujo enfoque está na compreensão dos mecanismos utilizados na construção da infância como objeto de interesse da pedagogia e da psicologia (GOUVÊA, 2008). Outras pesquisas salientam os processos de circulação e recepção de teorias psicológicas em foros educacionais brasileiros (RUCHAT, 2008). Ainda notamos textos cujo olhar recai sobre os laboratórios de psicologia experimental e suas contribuições para a pedagogia (MONARCHA, 2009; CIRINO; MIRANDA, 2014). Neste último tópico é que podemos ressaltar os pontos de diálogo do livro de Centofanti e Tomasini.

O livro se destaca, desde seu início, pela forma como foi escrito. Ao invés dos formalismos e da rigidez das normas acadêmicas, ele é escrito de maneira quase literária. Isso faz com que a narrativa seja fluida e a leitura fácil, agradável. Um exemplo disso é quando os autores discutem a efervescência cultural dos primeiros anos da República brasileira na capital paulista: "Publicações dos mais variados tipos, dirigidas a públicos específicos deixam claro que a vida econômica, social e cultural era intensa. Apurava-se uma espécie de crème de la crème no cadinho da economia" (CENTOFANTI; TOMASINI, 2014, p. 17). Não se espera, em um texto acadêmico, por exemplo, o uso da expressão "crème de la crème". Entretanto, isso não comprometeu a acurácia e o rigor metodológico na abordagem das fontes. Inclusive, uma parte da fluidez do texto se deve exatamente à escolha e ao tratamento das fontes primárias.

A documentação primária utilizada pelos autores é, em grande parte, composta por fotografias, reportagens e anúncios de época. $\mathrm{O}$ intuito inicial era produzir um "livro, nada menos, que até [dispensasse] textos. Fotos e legendas [bastariam]" (GUEDES, 2014, p. 7). Mesmo não sendo essa a forma de apresentação, o acervo fotográfico foi o carro-chefe da publicação. A obra conta com mais de 50 fotos, sendo que a maioria pertence aos arquivos pessoais dos pesquisadores, especialmente de Centofanti. Parte delas foi tratada digitalmente para que seus objetos pudessem se tornar visíveis, após a ação do tempo. Se por um lado isso aparenta ser um descuido metodológico em relação à iconografia, esse procedimento se mostra como um cuidado com o leitor e com a memória do objeto historicizado. Por 
conseguinte, o tratamento para a publicação das fotografias realizado pelos autores constitui um belo esforço de preservação documental. Tal documentação agora também está disponível para o público leitor da obra. Infelizmente, nem todas as fotografias ficaram bem visíveis. Algumas fotos ocupam página inteira - o que auxilia bastante na visualização de pessoas, espaços e objetos. Entretanto, outras tantas são minimizadas, de forma a se encaixarem junto com textos ou em conjunto com outras fotos. Estas, infelizmente, têm a visualização comprometida. A escolha a respeito da disposição das imagens pode ter sido feita com a finalidade de aumentar o seu espaço de reprodução, o que iria ao encontro do plano original dos autores. Pode, também, ter sido fruto da dificuldade de tratamento das fotos, isto é, aquelas cuja qualidade pós-tratamento permanecessem desfocadas, teriam de ser reduzidas em seu tamanho original.

No conjunto de fotografias, vemos vários aspectos para além da cultura material acessível à Escola e ao laboratório de psicologia. Por exemplo, há fotos em que as crianças atendidas pela Escola Normal nos primeiros anos dos 1900, são vistas e nas quais é possível notar construções diferentes para a apresentação dos meninos e das meninas. Os primeiros, assentados em carteiras em meio a lápis e papel, com um professor, altivo, ao fundo. As meninas, ao ar livre, usando chapéus e capas, com professoras, também bem vestidas. Outro exemplo, vinculado ao laboratório, são as fotografias que captaram os aparatos sendo manuseados. Há figuras nas quais vemos os professores da Escola em tal atividade, na presença de crianças como sujeitos "em teste". Outras fotos mostram a utilização de um local específico e de seus aparatos, ao longo do tempo. Por exemplo, há uma fotografia de Lourenço Filho e Noemy Silveira em 1927, com aparatos no laboratório de psicologia e uma criança. Em outra, vemos a criança manuseando um ergógrafo ${ }^{1}$ e o registro de seu comportamento sendo feito pelo quimógrafo ${ }^{2}$. Ao centro, ainda notamos aquilo que aparenta ser um metrônomo ${ }^{3}$. Os objetos, as pessoas e as suas formas de caracterização auxiliam o leitor a compreender os aspectos socioculturais das primeiras décadas da República brasileira. Em particular, propiciam-nos observar a confiança nos métodos e instrumentos de laboratório bem como na crença da ciência como fonte para a educação no país.

No campo de reportagens e anúncios, também podemos acessar aspectos da vida sociocultural da capital paulista nas primeiras décadas da República, e da disseminação da crença na ciência. As reportagens nos aproximam da Belle Époque brasileira, especialmente vinculada a São Paulo: urbana, com importações de tecnologias do 
cotidiano - carros, literatura, etc. Nessas reportagens, vemos desde matérias sobre o escritor Olavo Bilac até a promoção de salões de beleza. Há, também, o indicativo de que temas científicos circulavam no campo cultural da cidade. Existem reportagens escritas sobre os atores da Escola e do laboratório, tais como Clemente Quaglio e Oscar Thompson. Além disso, os jornais veiculavam assuntos relacionados à psicologia e a outras ciências, como a medicina. Em relação ao primeiro caso, Centofanti e Tomasini (2014) citam o Correio Paulistano, que, em 1909, publicou matéria intitulada "A Nova Teoria da Histeria". Em relação ao segundo, os autores mencionam A Cigarra, que publicava uma seção "A Medicina em São Paulo". Tais referências apontam para um contexto urbano e modernizante, no qual se inseriam a Escola Normal e o Laboratório de Psicologia nas primeiras décadas da República, elementos especialmente destacados pela classe intelectual e política paulistana.

A maneira de abordar a documentação primária e o objeto de pesquisa também é digna de nota. Para um leitor desavisado, a proposta dos autores poderia soar como uma lista de fotografias e descrições de aparatos de laboratório. Nessa lista, poderíamos ver os aparelhos, suas funções e a relevância que tinham na Escola Normal. Esse seria um esforço importante para compreender a psicologia e seus diálogos com a educação no período. Entretanto, o uso de reportagens, anúncios e imagens tem por objetivo dar ao leitor "o tom da época". A proposta é permitir, o máximo possível, perceber aquilo que se pensava - e como se pensava - em um determinado período da história brasileira. Dessa maneira, o intuito era apresentar: "Práticas e saberes [que] iam, paulatinamente, sobrepondo-se uns aos outros, num processo gerador de tensões, cujo registro cotidiano nos permite, assim, rever essa história, na medida do possível, dentro de seu próprio cenário" (CENTOFANTI; TOMASINI, 2014, p. 11).

Por exemplo, são cotejados debates sobre a ciência e a ortodoxia moral e religiosa, como no texto do advogado Spencer Vampré (1909, citado por CENTOFANTI; TOMASINI, 2014): "Muitas vezes os preconceitos materialistas têm agido tão fortemente no espírito dos pensadores que eles se têm contradito a si próprios. Pudera demonstrá-lo aqui com exemplos brilhantes de Charles Darwin e de Claude Bernard" (VAMPRÉ, 1909 citado por CENTOFANTI; TOMASINI, 2014). Ainda nessa direção, os autores cuidam da forma de abordar e apresentar as fontes primárias. Elas são abordadas como alvo de opções, recortes e seleções daqueles que produziam a documentação primária. As fontes, dessa forma, não são tomadas como retratos do real, especialmente as fotografias. Ao longo do 
texto, apresentam-se razões para que pessoas, em determinadas posições sociais, escolhessem as Escolas Normais como vetores de modernização. Motivos e debates sobre tais escolhas também são expostos, inclusive, para se compreender a tríade ciência experimental, laboratório e psicologia, na seara da educação. Salientam-se aspectos socioculturais do período, para conectar o debate sobre os pontos específicos relacionados à história da educação e da psicologia.

Além disso, há interpretações sobre os saberes e fazeres de diferentes personagens, deixando claro que os fatos passados resultaram em produtos de variadas intencionalidades de diferentes atores sociais. Em seus termos:

Escapando à ortodoxia e fugindo ao formalismo de linguagem, buscamos identificar tempo e lugar, espécie de palco onde se moveram atores que, bem ou mal, obedeciam aos imperativos de sua época, e buscavam, com a própria cidade, projetar-se rumo a um horizonte onde brilhavam o progresso e a ciência. (CENTOFANTI; TOMASINI, 2014, p. 11)

Nessa direção, podemos citar alguns exemplos: a trajetória de Ugo Pizolli - o "especialista" estrangeiro que montou o laboratório na Itália e como sua psicologia dialogava com seus contemporâneos europeus. Outro exemplo, as influências de Clemente Quaglio importante personagem da educação paulista - no que tange ao laboratório de psicologia e à própria psicologia aplicada à educação, em São Paulo. Os autores argumentam que a psicologia importada pela capital paulista, especialmente pela Escola Normal, era uma psicologia italiana: "O que acontecia aqui era consequência do que se passava no mundo, na Europa e, muito particularmente na Itália, país do qual São Paulo importou seu modelo de pedagogia científica" (CENTOFANTI; TOMASINI, 2014, p. 39). Ficam claros diversos pontos dessa asserção ao longo do texto: a escolha de Pizzoli, a ficha biográfica e os instrumentos de laboratório por ele produzidos, etc. Todavia, não fica em evidência de que forma essa psicologia italiana, interessada no campo educacional, dialogava ou diferia das produções europeias de seu período. Ao final do livro, há um vislumbre disso na crítica de Maria Montessori à psicologia experimental/pedagogia científica. Abordar aspectos nessa direção auxiliaria o leitor a compreender a ancoragem de Pizzoli, na Europa, e como suas propostas circularam no Brasil, especificamente na Escola Normal. Além do que isso contribuiria para pensar as diferentes psicologias interessadas na educação que circulavam no país no período, tais como a de Manoel Bonfim, no Rio de Janeiro, e a de Helena Antipoff, em Belo Horizonte. Talvez tal lacuna, no livro, transforme-se em um convite aos leitores para 
futuras pesquisas nos campos da história da educação e da psicologia. O trabalho de preservação documental, especialmente das fotografias, abre espaço para estudos sobre aqueles tempos e seus objetos, como também para análises comparadas e conectadas entre as Escolas Normais e seus laboratórios de psicologia experimental no país.

O livro dos cem anos do Laboratório de Psicologia Experimental da Escola Normal Secundária de São Paulo (1914-2014) cumpre seu papel celebratório. Ele se constituiu como preservação da memória de certos espaço e tempo, bem como de determinados atores. Além disso, conforme exposto, ele convida a novos estudos tanto no campo da história da psicologia, quanto da história da educação. A obra apresenta aportes metodológicos e documentais - jornais e fotos que têm merecido, cada vez mais, atenção dos campos temáticos da historiografia. Dessa maneira, celebrando o centenário do laboratório de psicologia experimental da Escola Normal Secundária de São Paulo, os autores atingem diferentes objetivos e convidam à leitura. Leitura da obra e do período histórico em análise.

\section{REFERÊNCIAS}

CAMPOS, R. H. F. História da Psicologia e História da Educação - Conexões. In: VEIGA, C. G.; FONSECA, T. N. L. (Org.). História e Historiografia da Educação no Brasil. Belo Horizonte: Autêntica, 2008. p. 129-158.

CENTOFANTI, R. Radecki e a Psicologia no Brasil. Psicologia: ciência e profissão, Brasília,v. 3, n. 1, p. 2-50, 1982.

CIRINO, S. D.; MIRANDA, R. L.. Psychology and Education in Brazil: The experimental psychology laboratory at the Belo Horizonte Teachers College. In: SOROKINA, M.; MASOLIKOVA, N. (Org.). The global educational space and academic migrants: the legacy of the Russian-Brazilian psychologist Helena Antipoff (1892-1974) in science, education and human rights (Latin America, Europe and Russia). Moscou: Alexander Solzhenitsyn Center for the Study of the Russian Diaspora, 2014. p. 157-173.

GOUVÊA, M. C. S. Estudos sobre Desenvolvimento Humano no Século XIX: da biologia à psicogenia. Cadernos de Pesquisa, São Paulo, v. 38, n. 134, p. 535-557, 2008.

GUEDES, M. C. Prefácio. In: CENTOFANTI, R.; TOMASINI, M. B. (Org.). O livro dos cem anos do Laboratório de Psicologia Experimental da Escola Normal Secundária de São Paulo (19142014). São Paulo: [s.e], 2014. p. 7-9.

MONARCHA, C. Brasil arcaico, Escola Nova: ciência, técnica e utopia nos anos 1920-1930. São Paulo: Editora UNESP, 2009.

RUCHAT, M. A Escola de Psicologia de Genebra em Belo Horizonte: um estudo por meio da correspondência entre Edouard Claparède e Hélène Antipoff (1915-1940). Revista Brasileira de História da Educação, Maringá, v. 8, n. 2, p. 181-205, 2008.

TOMASINI, M. B. Porto Alegre imaginada: cidade, cartas de amor e poesia. Revista LatinoAmericana de História, São Leopoldo, v. 2, n. 7, p. 438-451, 2013.

WARREN, H. C. Dictionnary of psychology. Cambridge: Houghton Mifflin, 1934. 


\section{NOTAS}

${ }^{1}$ Ergógrafo era um aparato utilizado para diferentes estudos, tais como os sobre fadiga e esforço muscular (WARREN, 1934). O participante sentava-se diante do instrumento e tinha seu braço preso a ele. O movimento era realizado com mãos e dedos fazendo com que diferentes pesos de movimentassem. A medida de esforço, por exemplo, era dada pela fadiga apresentada após a repetição de movimentos.

${ }^{2}$ Quimógrafo era um artefato utilizado para o registro de variações temporais em investigações que envolviam processos fisiológicos ou comportamentais (WARREN, 1934).

${ }^{3}$ Metrónomo era um equipamento utilizado para a mensuração de tempo a partir da oscilação constante de um pêndulo (WARREN, 1934).

Recebido: 22/12/2014

Aprovado: 08/07/2015

Contato:

Universidade de São Paulo (USP) Faculdade de Filosofia, Ciências e Letras (FFCLRP).

Departamento de Psicologia e Educação Av. Bandeirantes 3900, Monte Alegre Ribeirão Preto |SP|Brasil

CEP 14.040-901 
